\title{
Programa Bolsa Família: descentralização, centralização ou gestão em redes?
}

Pedro Luiz Cavalcante

\section{Introdução}

Os programas de transferência de renda, considerados a segunda geração de políticas sociais pós-Constituição Federal de 1988, são oriundos do consenso entre importantes setores do Estado e da sociedade brasileira acerca de ações enérgicas no combate à pobreza. Começaram a ser implementados a partir de 2001, à luz das diversas experiências de prefeituras municipais, principalmente sob o formato de Bolsa Escola. De modo geral, elas convergem pelo seu caráter focalizado e pela exigência do cumprimento de condicionalidades por parte dos beneficiários. Apesar de recentes, essas políticas têm chamado a atenção dos acadêmicos e de organismos multilaterais em função de seus resultados positivos e da célere proliferação em países emergentes.

O Programa de Transferência de Renda com Condicionalidades, também denominado Bolsa Família (PBF), constitui o principal programa de transferência de renda condicionada do governo federal e o maior da América Latina, tanto 
em orçamento quanto em cobertura ${ }^{1}$. Atualmente, atende a totalidade de famílias pobres do Brasil, ou seja, cerca de 11,1 milhões de famílias, e possui um orçamento para o exercício de 2008 de aproximadamente $\mathrm{R} \$ 10,8$ bilhões.

$\mathrm{O}$ PBF tem como objetivo oferecer proteção a todo grupo familiar e contribuir para seu desenvolvimento. Para tanto, fundamenta-se em três dimensões. Primeiro, a promoção do alívio imediato da pobreza por meio da transferência direta de renda. Segundo, o reforço ao exercício de direitos sociais básicos nas áreas de saúde, educação e assistência social pelo cumprimento das condicionalidades. E, por fim, a integração com programas complementares, que visa auxiliar e capacitar as famílias de modo que os beneficiários consigam superar a situação de vulnerabilidade e pobreza. (COHN e FonseCA, 2004).

O programa, criado em 2003, é resultante de um processo de unificação de quatro programas de transferência de renda (Bolsa Escola, Bolsa-Alimentação, Programa Cartão Alimentação e Auxílio-Gás). O argumento em prol da junção fundamentava-se na concepção de que o combate à pobreza e à exclusão de forma unificada tenderia à melhoria da gestão e do aumento da efetividade do gasto social. Dessa forma, o Bolsa Família introduziu algumas inovações nos programas de transferência de renda do governo federal, quais sejam: passou a proteger a família inteira, em vez de apenas o indivíduo; aumentou o valor dos benefícios pagos; simplificou a gestão de todos os programas em um só; exigiu maior compromisso das famílias atendidas; e potencializou as ações de governo, articulando União, Estados e Municípios.

No que tange ao último aspecto, o decreto que regulamentou o programa ${ }^{2}$, em seu Artigo 11, estabelece que a implementação e a gestão do Programa Bolsa Família se fundamentarão na descentralização, por meio da conjugação de esforços entre os entes federados, observada a intersetorialidade, a participação comunitária e o controle social. Logo, a gestão do PBF se fundamenta formalmente no processo de descentralização e democratização, assim como as mais consolidadas políticas sociais no Brasil: educação e saúde. A tese defendida tanto pelos formuladores quanto pelos gestores responsáveis pelo programa no governo federal é que a sua implementação deve priorizar as relações federativas, fortalecendo a gestão compartilhada não apenas com os atores governamentais como também com os não governamentais.

M.H.T. Almeida (2005) argumenta, entretanto, que o PBF caminhou no sentido oposto das demais políticas sociais no Brasil, isto é, rumo a um modelo centralizador da gestão. Ficam claras, então, duas perspectivas antagônicas acerca do programa.

$\mathrm{O}$ artigo analisa como se desenvolveu o processo de implementação e seu consequente modelo de gestão, no cerne do debate centralização-descentralização, após cinco anos de existência do programa. A hipótese do estudo é que o PBF não apenas caminhou para o fortalecimento da descentralização, superando alguns desafios da consolidação do "pacto federativo" e criando incentivos financeiros e técnicos aos governos subnacionais, em especial à gestão municipal, como também construiu uma configuração mais complexa, próxima da gestão em redes.

O artigo está organizado em três partes. Na primeira, é apresentada uma discussão teórica acerca do federalismo, descentralização das políticas sociais e 
conceito de redes de políticas públicas. Em seguida, são discernidas as principais estratégias de implementação do PBF, de modo a contextualizá-lo no debate e a discutir qual é efetivamente o desenho da sua gestão. Por fim, algumas considerações são esboçadas no intuito de corroborar com a hipótese da pesquisa.

\section{Políticas Sociais: federalismo, descentralização e redes}

Esta parte procura apresentar uma discussão acerca de temas centrais para a compreensão da evolução da gestão das políticas sociais no Brasil. Primeiro, os conceitos de federalismo são expostos e contextualizados ao caso brasileiro. Em seguida, discute-se a descentralização com ênfase nas interpretações desse processo, na área social. E, finalmente, é apresentada a definição de redes e de como elas operam no campo das políticas públicas.

\section{Federalismo}

Um Estado Federal ou Federação pressupõe que a ação de dois ou mais governos seja exercida simultânea e harmonicamente sobre o mesmo território. A soberania do Estado é única, o que é repartido é a autonomia dos entes federados. Já o federalismo consiste em uma estrutura de poder dentro de uma distribuição territorial articulada e compartilhada entre o poder nacional (soberano) e os poderes regionais e/ou locais. De acordo com Almeida, o federalismo é:

um sistema baseado na distribuição territorial de poder e autoridade entre instâncias de governo, constitucionalmente definida e assegurada, de tal forma que os governos nacional e subnacionais sejam independentes na sua esfera própria de ação (ALMEIDA apud AfFonso e SiLVA, 1996, p. 36).

O modelo compartilhado de poder se origina a partir de um acordo formal, normalmente uma Constituição, que estabelece as regras da integração e as competências das partes autônomas. Ao incorporar tais características, o federalismo está presente em vários sistemas políticos contemporâneos. Por conseguinte,

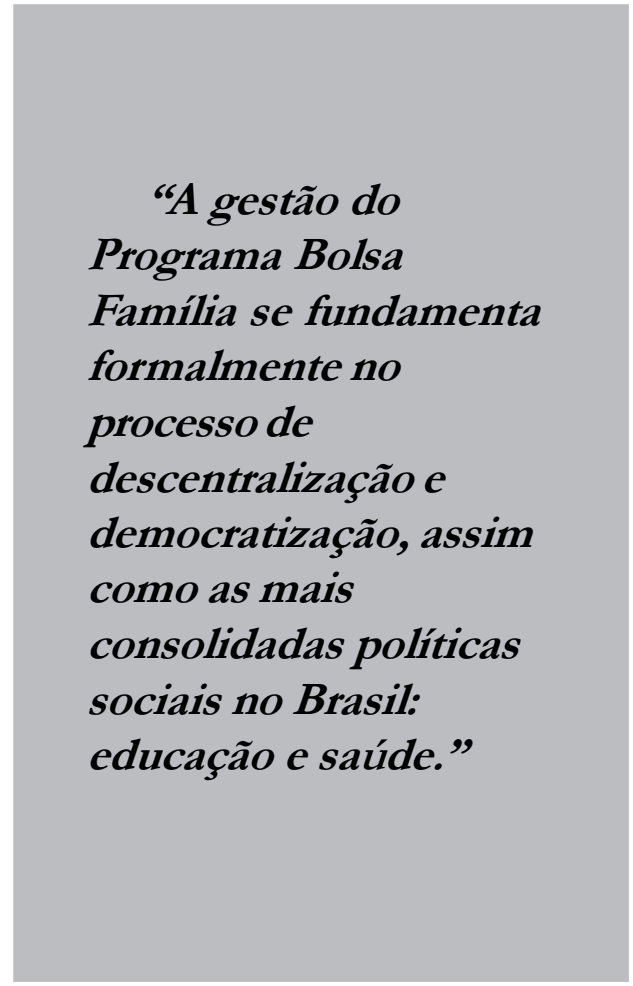

algumas tipologias de federalismo foram criadas de modo a enquadrar a diversidade de formatos das relações entre governos dentro de um Estado Federal. Uma importante classificação é a de Acir (1981), desenvolvida para analisar o sistema federal norte-americano, que apresenta formas de arranjos federativos. O primeiro é o federalismo dual, no qual os poderes nacionais e subnacionais são exercidos no 
mesmo território, entretanto com soberanias diferentes, separadas e independentes. O segundo modelo é o federalismo centralizado, que consiste em um arranjo institucional cujos governos subnacionais atuam mais como agentes administrativos do governo federal do que propriamente autônomos. O último é o federalismo cooperativo, que envolve a parceria das ações das diferentes esferas de governo, cujos governos regionais mantêm autonomia e controle sobre seu financiamento.

Enquanto o primeiro tipo caiu em desuso, os pressupostos dos dois últimos permeiam a configuração das relações intergovernamentais nos Estados federais, nos dias de hoje. Ambos convivem nesses sistemas políticos, alternando sua predominância de acordo com fatores temporais, espaciais, bem como conforme as áreas de atuação dos governos (AlmeidA, 2005). Em outras palavras, uma relação federativa possui distintas configurações, no que concerne a políticas específicas. Por exemplo, políticas públicas na área tributária possuuem arranjo federativo distinto do arranjo federativo de políticas públicas na área social. No Brasil, a Constituição de 1988 estabeleceu que o sistema federativo é cláusula pétrea e introduziu a figura dos municípios como entes autônomos e independentes, fato inédito nos sistemas federalistas do mundo. Com efeito, no Brasil, os níveis de governo - União, estados, municípios e o Distrito Federal, que acumula competências estaduais e municipais - possuem significativa autonomia administrativa e atribuições em distintas políticas públicas, bem como capacidade de financiamento. Esse arranjo demonstra a transição do federalismo centralizado para o cooperativo, implementado pela Assembleia Constituinte. Entretanto, a complexidade do arranjo federativo brasileiro apresenta tendências simultâneas, tanto centralizadoras quanto descentralizadoras, variando de acordo com os atores e interesses envolvidos (ARretche, 2000; AlmeidA, 2005; ABrucio, 2006). Na mesma direção, Celina Souza discorre acerca das dificuldades da consolidação do federalismo cooperativo no Brasil:

Existência de duas razões que impedem o alcance do federalismo cooperativo: diferentes capacidades dos governos subnacionais de implementarem políticas públicas, dadas as enormes desigualdades financeiras, técnicas e de gestão existentes e a ausência de mecanismos constitucionais ou institucionais que regulem as relações intergovernamentais e que estimulem a cooperação, tornando o sistema competitivo (Souza, 2005, p. 118).

Os obstáculos mencionados por Souza (2005) são mais perceptíveis na política fiscal, em que diversas ações com vistas a solucionar o problema da guerra fiscal têm sido inócuas no decorrer das últimas décadas. Todavia, é notório que muito tem-se evoluído no sentido da superação dessas dificuldades, particularmente no âmbito dos programas de cunho social, como veremos a seguir.

\section{Descentralização}

No campo das políticas sociais, segundo Almeida (1996), o país caminhou da transição do federalismo centralizado - reflexo do nosso histórico de governos totalitários - para um federalismo cooperativo, descentralizado, pós-Constituição de 1988. Tal arranjo, em célere fase de construção, pressupõe o fortalecimento de parcerias com base na definição clara 
de competências compartilhadas e de um processo de negociação de caráter de jogo de soma positiva, isto é, o ganho de um ator não necessariamente resulta na perda de outro.

Contudo, qual o significado de descentralização? Assim como federalismo, o termo também não possui uma miríade de conceituações. De acordo com Abrucio (apud Fleury, 2006), a descentralização é um processo complexo, relativamente recente na administração pública, tendo papel de destaque somente nas últimas décadas do século XX e pode ser associado à crise do modelo centralizador e às novas realidades, como a democratização do poder público e as demandas por melhorias do desempenho governamental.

A descentralização ocorre em duas frentes: uma de caráter estritamente político, que inclui a transferência de poder e autonomia ao ente subnacional, o que implica a existência de assembleias legislativas regionais e estrutura tributária própria; e outra mais restrita à gestão, que consiste na delegação de funções no processo de implementação e execução das políticas públicas. É sobre a segunda perspectiva que este artigo se debruça. Arretche, na análise das políticas sociais, argumenta:

Descentralização significa genericamente a institucionalização no plano local de condições técnicas para a implementação de tarefas de gestão de políticas sociais (ARRETCHE, 2000, p.16).

Em outra definição, o Banco Mundial defende que descentralização se fundamenta na transferência de autoridade e responsabilidade de questões públicas do governo central para governos locais ou intermediários, para organizações governamentais semi-independentes e/ou para o setor privado (WORLD BANK, 2002). Esse conceito apresenta uma visão abrangente do fenômeno, que ultrapassa a fronteira das relações federativas, incluindo ainda o terceiro setor e a iniciativa privada. De modo geral, pressupõe que a descentralização incorpora a ideia de ampliação da ação compartilhada, haja vista a constante evolução das atribuições do Estado.

$\mathrm{Na}$ nova realidade brasileira pós-1988, a descentralização ganha mais relevância, tendo em vista que a estrutura federativa possui três, e não apenas dois entes. Por conseguinte, a descentralização não ocorre somente a partir da transferência de responsabilidades e funções do nível federal para o estadual, mas também do federal para o municipal e do estadual para o municipal. Sem contar com a participação de atores mais recentes, como organismos não governamentais, empresas privadas e organizações sociais de interesse público (Oscip), que cada vez mais têm desempenhado papel de destaque na gestão de políticas públicas no país.

Apesar da complexidade de atores e estruturas, permanece a predominância da responsabilidade governamental. No entanto, a decisão e a gestão de cada uma das políticas sociais variam de acordo com a área específica, bem como as características e condições das diferentes regiões do país. Nesse aspecto, a diversidade das formas de cooperação entre as instâncias de governo é originária do desenho institucional definido pela Constituição Federal de 1988.

Nos debates da Assembleia Constituinte, a defesa da descentralização de responsabilidades se explicava como uma forma de ampliação da democracia, da eficiência e eficácia das ações do governo (AlmeidA, 2005). Aliado à aversão ao centralismo burocrático das ações 
governamentais vigente durante os governos militares e ao consenso de que a extensão do território nacional requeria iniciativas conjuntas e pautadas no conhecimento das particularidades de cada região, os constituintes optaram pelo formato das competências concorrentes e de gestão compartilhada com os governos estaduais e municipais, principalmente nas políticas sociais.

No artigo 23, a Constituição Federal define competências comuns para União, estados e municípios nas áreas de saúde, assistência social, educação, cultura, habitação e saneamento, meio ambiente, proteção do patrimônio histórico, combate à pobreza e educação para o trânsito. No entanto, fica a cargo da legislação complementar estabelecer as formas de interação das esferas de governo. Nesse ponto, algumas áreas já aprovaram suas normatizações, tais como a saúde, a educação e a assistência; outras ainda se encontram em fase de tramitação. Logo, as primeiras tendem a possuir estrutura de relações federativas mais consolidada do que as demais.

Em certas políticas, optou-se pela transferência aos entes subnacionais da prerrogativa de decidir o conteúdo e o formato dos programas; em outras, os governos estaduais e municipais tornaram-se responsáveis pela implementação e gestão de políticas e programas definidos em nível federal (ARRETCHE, 2004). Observa-se, então, um processo heterogêneo de descentralização das políticas sociais, influenciado pela importância da temática na agenda governamental, pelo desenho de cada política específica e pela distribuição prévia de competências e do controle sobre os recursos entre as esferas de governo.

Em suma, a Constituição de 1988 institui um processo de descentralização, especialmente de municipalização, dos ser- viços públicos básicos mediante a definição de macrorresponsabilidades. Todavia, isso não implicou a imediata efetivação de uma gestão compartilhada. A partir daí, cada área necessitava desenvolver os mecanismos de coordenação e cooperação intergovernamental, de modo a colocar em prática os pressupostos constitucionais, como bem expõe Mesquita:

Do ponto de vista da implementação de políticas sociais, a descentralização no modelo federativo não ocorre de forma automática, em uma abordagem de cima para baixo. Pressupõe adesão, barganhas, estratégias de indução, espaços de coordenação intergovernamental (MESQUITA, 2006, p.471).

A disparidade entre as regiões, estados e municípios brasileiros no tocante às capacidades financeiras dos pequenos municípios, à deficiência de recursos humanos e à estrutura física para gerir as políticas sociais era o principal obstáculo para a consolidação da descentralização. O governo federal é o protagonista da coordenação federativa, em função da sua posição estratégica em relação aos governos subnacionais, do papel de principal financiador e de normatizador (Almeida, 1996; Affonso e Silva, 1996).

Consequentemente, a trajetória da descentralização das políticas sociais brasileiras é influenciada pelo posicionamento do governo federal. As ações no sentido de estruturar a coordenação e cooperação das políticas sociais nos governos Sarney, Collor e Itamar não foram expressivas. Apenas a partir de 1995, é possível verificar uma estratégia decisiva do governo federal no sentido de efetivar a parceria com os estados e municípios na gestão das políticas sociais, 
como é detalhado por Arretche em trecho a seguir:

A existência de políticas deliberadas, explícita e eficientemente desenhadas para obter a adesão dos governos locais, é uma condição necessária ao sucesso de um processo amplo e abrangente de transferência de funções de políticas sociais. Isto implica dizer que, para obter resultados na transferência de atribuições, a ação política deliberada pode alterar substancialmente o peso e a importância de variáveis relacionadas aos atributos estruturais de estados e municípios e aos atributos institucionais das políticas (ARRETCHe, 2000, p.244).

Dessa forma, o governo federal precisa elaborar uma estrutura de incentivos à participação das unidades subnacionais, de modo a superar as limitações dessas do ponto de vista financeiro e administrativo. Assim, possibilitará que os governantes locais visualizem mais benefícios do que custos ao aderirem à gestão compartilhada de uma determinada política social.

A estrutura de incentivos e a consequente propensão à descentralização de cada política estão vinculadas a suas disposições constitucionais, ao desenho de um programa de descentralização e a seu modo efetivo de implementação (ARRETChe, 2004). É possível compreender as razões que levaram a configurações distintas de política social no país. Entretanto, a literatura converge na concepção de que a descentralização norteou o desenvolvimento da grande maioria dos processos de implementação e gestão das políticas sociais pós-Constituição, sendo o Sistema Único de Saúde (SUS) o caso mais consolidado de gestão compartilhada entre as três esferas de governo.
E como evolui essa nova área das políticas públicas no que diz respeito à transferência de renda com condicionalidades? Antes de entrarmos no caso Bolsa Família, o conceito de redes de políticas públicas é apresentado.

\section{Redes de Políticas Públicas}

O estudo de redes no campo das políticas públicas é um fenômeno recente, que surge como resposta à complexificação da

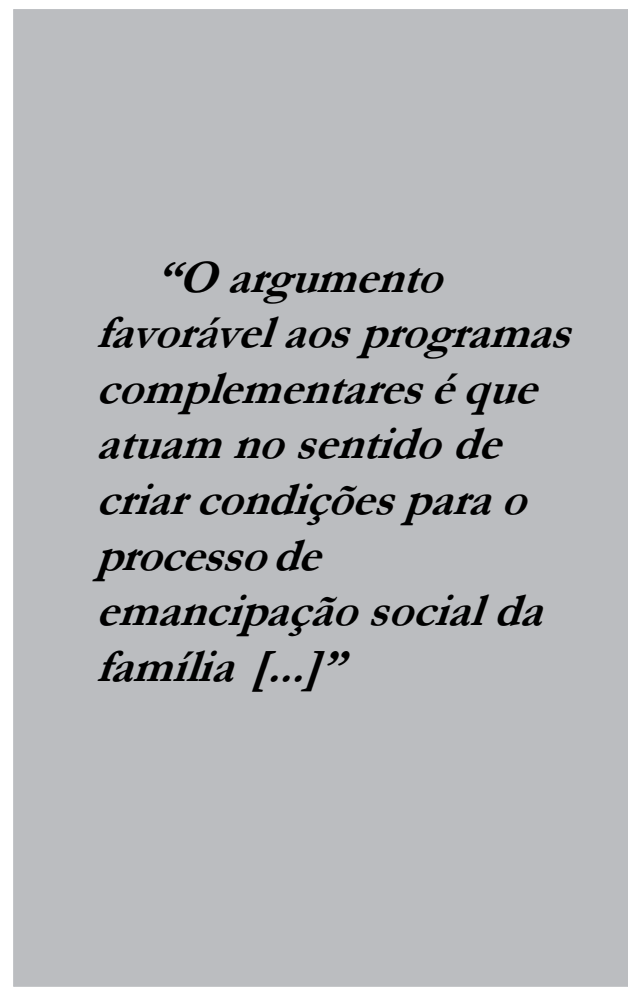

administração pública e aos consequentes desafios impostos a ela. A constante democratização e a evolução da tecnologia da informação ampliaram o número de atores, interesses e demandas da sociedade civil. O Estado, então, viu-se obrigado a construir modelos de gestão que se adaptam à nova realidade, incorporando outras formas de interação com estruturas descentralizadas e métodos inovadores de 
parcerias com uma diversidade de atores governamentais ou não governamentais, de modo a superar problemas de comunicação e cooperação.

Redes de políticas públicas ou policy network apresentam uma variedade de definições. De acordo com Börzel, consistem "num conjunto de relações relativamente estáveis, de natureza não hierárquica e independente, que vinculam uma variedade de atores que compartilham interesses comuns em relação a uma política e que trocam entre si recursos para perseguir esses interesses comuns, admitindo que a cooperação é a melhor maneira de alcançar as metas comuns" (BÖRZEL, 1998, p.254).

A partir desse conceito, nota-se que os princípios de horizontalidade e interdependência da relação são vitais, ou seja, as interações dentro das redes não obedecem a critérios de hierarquia e/ou de subordinação. Isso não implica dizer que haja distribuição homogênea de responsabilidades e recursos.

Essa repartição indica a existência de múltiplos atores com funções específicas que não necessariamente seguem ordenamento, o que configura um processo de políticas públicas mais fluido, distinto da concepção de etapas sequenciais. Nesse sentido, a institucionalização de regras formais e informais de interação é o mecanismo utilizado para estabelecer as atribuições dos atores, a repartição dos recursos e os incentivos à participação dentro das redes de políticas públicas.

Outra variável importante na conceituação de Börzel(1998) é o objetivo comum compartilhado que ultrapassa as questões particulares. A motivação para a formação das redes pode envolver princípios comuns, obrigações legais e institucionais, interesses, pressões e demandas da sociedade civil. A partir daí, a estrutura de redes se posiciona no sentido de alcançar sua missão comum, mediante a institucionalização de padrões interativos e de intercâmbio constante de recursos.

Esse conceito mais amplo de gestão das políticas públicas está diretamente relacionado à descentralização, entretanto, incorpora mais variáveis na abordagem. A gestão ou governança em redes pressupõe maior vinculação entre governo e sociedade em uma estrutura horizontalizada, na qual a institucionalização das relações formais e informais se fundamenta na interdependência de recursos e na definição de atribuições em prol de objetivos comuns. De acordo com Fleury e Ouverney (2007), trata-se de um processo de participação de múltiplos atores, que se inicia na definição de uma agenda de políticas compartilhadas até a efetiva implementação de programas, direcionada à melhoria da eficiência e eficácia das políticas públicas.

\section{Implementação e gestão do PBF}

O Programa Bolsa Família (PBF) foi formulado a partir da articulação intersetorial de ministérios das áreas social e econômica, sob a coordenação da Casa Civil e da Assessoria da Presidência da República, e lançado em 20 de outubro de 2003. Após um breve período na Presidência, a gestão do programa foi transferida para o Ministério do Desenvolvimento Social e Combate à Fome (MDS). Nessa pasta, a Secretaria Nacional de Renda de Cidadania (Senarc) é a responsável pela coordenação, gestão e operacionalização do programa.

De acordo com M.H.T. Almeida, a concepção e a implementação do programa se posicionaram de forma oposta às demais políticas sociais no Brasil, caracterizando-se como modelo centralizado de gestão, como exposto no trecho a seguir: 
Uma nova geração de políticas sociais - programas focalizados de transferência direta de renda - significou uma ruptura com o modelo prévio de federalismo cooperativo, predominante na área social, e uma volta clara às formas centralizadas de prestação de benefícios sociais [...] enquanto arranjos com diferentes graus de descentralização e a cooperação intergovernamental predominam nas áreas tradicionais de política social, as novas iniciativas dirigidas aos segmentos mergulhados na pobreza extrema reintroduziram a centralização da decisão, recursos e implementação na esfera federal (Almeida, 2005, p.38).

Mesquita, por sua vez, defende que os programas de transferência de renda implementados pelo governo federal no início da década já preconizavam a articulação entre a esfera nacional e os governos subnacionais, em especial as prefeituras, seguindo o mesmo caminho da saúde e educação. Os obstáculos operacionais de implantação de programas de ampla magnitude pautavam as decisões no processo de formulação desses, como bem destaca a autora:

É impensável imaginar que a União seja capaz isoladamente de realizar programas dessa natureza sem que os governos municipais estivessem dispostos a assumir as tarefas de cadastramento das famílias, de acompanhamento das condicionalidades, de fiscalização, bem como de atendimento da população (MesquiTA, 2006, 477).

Diante desses desafios, a formulação do Bolsa Família procurou inserir no seu desenho normativo e na subsequente estrutura administrativa a preocupação com o estabelecimento de parcerias com diferentes áreas do governo, estados, municípios e setores da sociedade civil. Desse modo, os princípios da intersetorialidade, descentralização, transparência e controle social na gestão seriam atendidos. Formalmente, esses pressupostos estiveram presentes no processo de elaboração do programa, no desenho normativo e na estrutura administrativa da secretaria responsável. Todavia, na prática, eles se efetivaram no decorrer da implementação do PBF?

Para responder à questão serão analisadas as estratégias mais importantes empreendidas durante o processo de implementação do programa, de modo a auxiliar a verificação da hipótese do artigo, qual seja: o PBF não apenas caminhou para o fortalecimento da descentralização, superando alguns desafios da consolidação do "pacto federativo" e criando incentivos financeiros e técnicos, em especial para a gestão local, como também construiu uma configuração mais complexa, próxima da gestão em redes.

\section{Condicionalidades}

As condicionalidades são os compromissos nas áreas de saúde, educação e assistência social que as famílias atendidas devem cumprir para assegurar a continuidade no recebimento do benefício financeiro do $\mathrm{PBF}$, com vistas a ampliar o acesso dos cidadãos aos direitos sociais básicos. Cabe salientar que elas não são uma inovação do PBF, mas sim originárias dos programas Bolsa Escola, Bolsa-Alimentação e Programa de Erradicação do Trabalho Infantil (Peti), integrado ao Bolsa Família em 2005³.

Os compromissos incluem o monitoramento da saúde das crianças e gestantes, da frequência escolar de $85 \%$ das crianças 
e adolescentes de seis a 17 anos e da garantia da frequência mínima de $85 \%$ da carga horária relativa às ações socioeducativas e de convivência para crianças e adolescentes de até 15 anos, retiradas do trabalho precoce, no âmbito do Peti. Nota-se, portanto, o caráter de intersetorialidade do programa na medida em que pressupõe ações nessas três áreas das políticas públicas.

A sua operacionalização requer a constante articulação federativa, não apenas no sentido da efetiva provisão desses serviços públicos básicos como também no monitoramento do seu cumprimento pelos órgãos municipais de educação, saúde e assistência social. Assim, as condicionalidades refletem tanto a integração horizontal quanto a vertical. A primeira se estabelece na participação dos ministérios da Educação e Saúde, como também da Secretaria Nacional de Assistência Social (SNAS), gestora do Peti. Já a integração vertical envolve os estados e municípios que não apenas proveem os serviços mas também subsidiam o MDS com informações para a continuidade do pagamento de benefícios às famílias ou para possíveis sanções.

\section{Cadastro Único}

Outro instrumento proveniente dos programas remanescentes é o Cadastro Único dos Programas Sociais do Governo Federal (CadÚnico), que consiste na base de dados sobre a localização e as características das famílias com renda per capita de até meio salário mínimo em todo o país. A partir das informações contidas no sistema do CadÚnico, a família é selecionada e inserida no PBF. A inclusão das informações nesse sistema, operacionalizado pela Caixa Econômica Federal, é de responsabilidade dos municípios, embora a seleção das famílias seja realizada pela Senarc com base em critérios de cobertura de atendimento de cada cidade e do perfil das famílias.

Inicialmente, as atividades de cadastramento de famílias acarretavam ônus às prefeituras municipais, sem contanto prover dividendos políticos aos prefeitos, uma vez que o programa é vinculado à imagem do governo federal. A única pressão pelo efetivo cadastramento das famílias era da própria população, considerando a ausência de obrigação intergovernamental nesse aspecto. O cenário gerou um impasse que poderia comprometer o cumprimento da meta de expansão do programa, isto é, atingir a totalidade de famílias pobres do país até meados de 2006.

Diante disso, no decorrer de 2005, a Senarc procurou intensificar o aprimoramento da relação com os governos subnacionais mediante a formalização de termos de adesão desses entes, principalmente os municípios, ao Bolsa Família e ao CadÚnico. Após a adesão, os municípios passaram a possuir responsabilidades no que tange ao cadastramento, monitoramento das condicionalidades, gestão de benefícios e oferta de programas complementares, enquanto aos estados a adesão implicou o compromisso de apoio aos municípios no processo de atualização cadastral e no desenvolvimento de atividades de capacitação e apoio técnico e logístico, entre outras. Além disso, ambas as esferas foram obrigadas a formar instâncias de controle social (ICS) compostas por integrantes do poder público e da sociedade civil. O processo foi considerado um sucesso, haja vista que mais de $99 \%$ dos municípios e a totalidade dos estados aderiram ao programa.

Como contrapartida, o governo federal estabeleceu responsabilidades mais 
claras perante os demais entes. Entre elas, passou a apoiar financeiramente as administrações locais de modo a ampliar e atualizar o cadastro das famílias pobres. A partir de julho de 2005, o MDS repassava aos municípios $\mathrm{R} \$$ 6,00 para cada cadastro atualizado, incluído ou complementado, desde que tivessem assinado o termo de adesão. $\mathrm{O}$ resultado foi positivo, na medida em que a meta de expansão do programa foi cumprida conforme planejado. No entanto, vale destacar que, embora o ministério tenha definido de que modo os recursos deveriam ser aplicados, o controle foi estritamente baseado nos resultados dos cadastros e não na aplicação das verbas.

Após o cumprimento da meta, a estratégia de pagamento por cadastro foi substituída pelo Índice de Gestão Descentralizada (IGD), um indicador de qualidade de gestão. Esse mecanismo se baseia na gestão municipal do Cadastro Único e no acompanhamento das condicionalidades. O cálculo do repasse financeiro é realizado mensalmente, multiplicando um valor de referência de $\mathrm{R} \$ 2,50$ por família beneficiária no município pelo IGD, que varia de 0 a 1 . Para os estados, o repasse também é mensal, em parcelas fixas, levando em consideração o número de famílias pobres de cada localidade e pautado em um plano de ação que contemple, principalmente, ações de capacitação, apoio técnico e logístico aos municípios e emissão de documentação.

Em suma, as estratégias de adesão formal e de apoio financeiro obtiveram o resultado planejado em um primeiro momento, haja vista que se ampliou o cadastro das famílias, possibilitando o cumprimento da meta de expansão. Em seguida, o MDS implementou o IGD de modo a dar continuidade ao apoio aos governos subnacionais, criando condições para que várias competências da execução local do programa se aprimorem. Nesse sentido, percebe-se o fortalecimento da gestão compartilhada, particularmente com os governos municipais. $\mathrm{O}$ governo federal procurou sanar as dificuldades das administrações por meio de apoio técnico e financeiro, ao mesmo tempo em que consolidou as relações, via instrumentos formais de parceria, em consonância com os padrões de implementação de políticas sociais pós-Constituição de 1988.

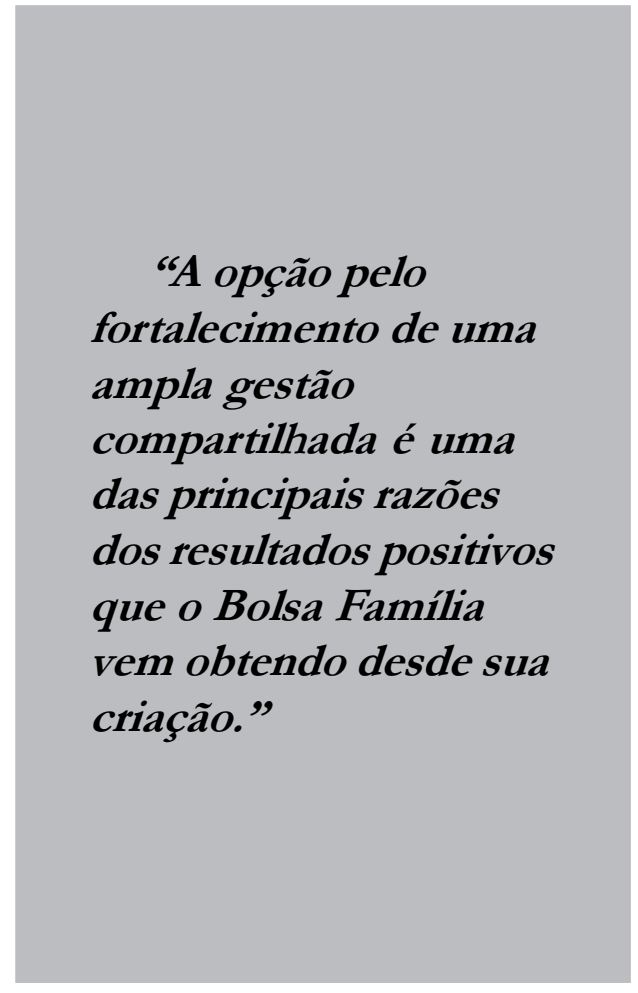

Gestão de Benefícios

A gestão de benefícios do PBF envolve uma série de atividades que englobam a manutenção, o bloqueio e o cancelamento dos benefícios das famílias. No início do programa, tais ações eram desenvolvidas exclusivamente pela Senarc, com base nas informações encaminhadas pelas prefeituras e órgãos de controle, normalmente 
via comunicado oficial. Esse procedimento configurava-se em um processo burocratizado, lento e custoso, tendo em vista a dificuldade operacional de processamento de milhares de ações todo mês.

Diante desse panorama, em 2005, a Senarc institui a gestão descentralizada de benefícios, na qual os municípios passaram a realizar essas atividades diretamente em um sistema via internet com mais autonomia, o que culminou em um processo mais eficaz, eficiente e célere. $\mathrm{O}$ único pré-requisito para a utilização do Sistema de Gestão de Benefícios (Sibec) é a assinatura do termo de adesão ao programa.

O acesso ao sistema também é disponibilizado aos gestores estaduais, aos integrantes das instâncias municipais e estaduais de controle social e aos membros da rede pública de fiscalização do PBF. No entanto, diferentemente dos gestores municipais, os usuários não podem exercer atividades de gestão de benefícios, apenas utilizam o sistema como instrumento de consulta.

Como resultado, observa-se a transferência de atribuições e autonomia à execução local do programa, atendendo ao princípio da descentralização. Ao mesmo tempo, isso possibilita a ampliação do controle tanto estatal quanto da sociedade civil sobre as atividades de gestão de benefícios, contemplando, assim, os princípios da transparência, participação e controle social.

\section{Pactuação}

A pactuação dos programas de transferência de renda consiste na integração dos programas já existentes dos estados e municípios ao PBF. O principal objetivo da implementação conjunta desses programas é criar condições para eliminar as superposições de ações e custos admi- nistrativos, aumentar a cobertura ou elevar os valores dos benefícios. Para tanto, o MDS assinou termos de cooperação específicos com os governos estaduais e municipais em duas modalidades distintas: com cofinanciamento e sem complementação do benefício por parte dos governos subnacionas.

Apesar da pactuação estar presente na implementação do PBF desde a sua origem, ela tem sido cada vez mais enfraquecida. Enquanto em 2004, 13 governos estaduais, o governo do Distrito Federal e 15 prefeituras pactuaram com o Bolsa Família, em 2007 apenas um estado, quatro municípios e o Distrito Federal mantiveram seus termos de cooperação vigentes. O decréscimo devese, por um lado, à inexistência de uma clara definição de atribuições por parte dos estados e municípios; e por outro, ao fato de também haver poucos benefícios políticos para esses entes, uma vez que o reconhecimento por parte das famílias atendidas é mais vinculado ao governo federal.

Aliado a isso, Fonseca e Viana (2007) argumentam que desde a criação do Bolsa Escola federal, os programas de iniciativa municipal e estadual começaram a ser desativados, principalmente em municípios pobres, sendo substituídos pelo programa federal. A pactuação demonstrou ser uma estratégia mais complexa de cooperação, que trouxe poucos resultados efetivos.

\section{Programas Complementares}

O argumento favorável aos programas complementares é que atuam no sentido de criar condições para o processo de emancipação social da família, ou seja, desenvolver as capacidades das famílias beneficiárias do PBF, auxiliando-as a superar a situação de pobreza e de vulnerabilidade 
social em que se encontram e apoiando-as na inserção no mercado de trabalho de forma sustentável. Desse modo, as ações complementam e potencializam os efeitos da transferência de renda e tendem a promover a tão debatida 'porta de saída'do Bolsa Família.

Embora a legislação do PBF e o termo de adesão estabeleçam que os governos federal, estadual e municipal têm responsabilidades na oferta e na articulação dos programas complementares, os resultados ainda são incipientes. O panorama indica a ausência de uma coordenação efetiva da estruturação de parcerias e do desenvolvimento de incentivos aos governos subnacionais e aos demais órgãos do governo federal na promoção dessas ações. Ademais, Mesquita (2006) ressalta que esse é um dos principais desafios do programa, tendo em vista que sua execução depende de visão territorial e da identificação de potencialidades regionais.

Quanto às medidas, no governo federal algum esforço tem sido empreendido no sentido de integrar horizontalmente o PBF a outros programas, principalmente da área social, como o Brasil Alfabetizado, Luz para Todos e o PróJovem. Mas a integração intragovernamental carece de formalização e de estruturação de competências.

Em relação aos governos subnacionais, a situação é ainda mais embrionária. Apesar de os estados e municípios, ao assinarem o termo de adesão, terem-se comprometido em ampliar a oferta de programas complementares, na prática os resultados têm sido pouco animadores. Contudo, vale salientar a iniciativa da Senarc de promover o Prêmio Práticas Inovadoras na Gestão do Programa Bolsa Família, em segunda edição, que cria incentivos para o desenvolvimento de programas complementares ao $\mathrm{PBF}$.

\section{Rede Pública de Fiscalização}

Em janeiro de 2005, o MDS procurou fortalecer o controle e a fiscalização do programa diante de inúmeras irregularidades e problemas detectados. O diagnóstico indicava, principalmente, que as falhas na comunicação com os gestores locais e com a sociedade civil acarretavam condutas indevidas por parte das prefeituras e recebimento de benefícios por cidadãos fora do público alvo do PBF.

A fim de amenizar esses problemas, a Senarc passou a desenvolver medidas com vistas a ampliar a informação acerca do Bolsa Família e fortalecer o controle e a transparência. Entre essas, vale destacar a formação da Rede Pública de Fiscalização, que consiste na parceria de desenvolvimento e aprimoramento do processo de fiscalização, avaliação e monitoramento do $\mathrm{PBF}$, dos programas remanescentes e do Cadastro Único, mediante termos de cooperação técnica entre o MDS e os principais órgãos de controle do país.

Os termos de cooperação foram assinados com os ministérios públicos federal e estaduais, a Controladoria Geral da União (CGU) e o Tribunal de Contas da União (TCU), tendo como objetivo central aperfeiçoar os instrumentos de fiscalização da execução do PBF, por meio do compartilhamento de esforços e informações com o MDS.

A despeito de uma avaliação sobre a efetividade da Rede Pública de Fiscalização, constata-se a tentativa de integração do PBF tanto horizontal, com órgãos da União, quanto vertical, uma vez que os ministérios públicos estaduais fazem parte da estrutura dos estados, e não da União.

\section{Instâncias de Controle Social}

Conforme já debatido, outros princípios que regem o $\mathrm{PBF}$ são a participação 
e o controle social. De modo a colocar em prática tais pressupostos, a Senarc incluiu no processo de adesão ao programa a obrigatoriedade de se formar instâncias de controle social (ICS) nas prefeituras e nos governos estaduais. Havia a possibilidade de indicação de um conselho já existente, que poderia desempenhar as tarefas relativas ao Bolsa Família, desde que houvesse paridade entre representantes do governo e da sociedade e composição intersetorial.

Cabe às ICS, entre outras atribuições, fiscalizar o processo de cadastramento das famílias pobres, acompanhar a gestão de benefícios e o cumprimento das condicionalidades das famílias, bem como estimular a integração e a oferta de programas complementares ${ }^{4}$.

Trata-se, portanto, de dezenas de milhares de pessoas debatendo e atuando no acompanhamento do programa, sendo boa parte delas oriunda de outros conselhos e áreas de políticas públicas. Os representantes da sociedade civil são provenientes também de entidades diversas, tais como sindicatos, igrejas e associações de bairro. Com efeito, esse enorme contingente introduz uma dinâmica diferente à gestão do programa, incorporando mais transparência e accountability ${ }^{5}$ às ações do poder público, dentro de um processo de integração basicamente extragovernamental.

\section{Conclusões}

O artigo procurou debater como o processo de implementação do Programa Bolsa Família se enquadra no debate acerca de descentralização, centralização e redes de políticas públicas. A partir da exposição da concepção do programa e das principais estratégias desenvolvidas pela gestão federal do PBF, é possível refutar a tese defendida por Almeida (1996), de que o programa se configura como centralizador.

A análise demonstra que o governo federal desempenha o papel central na gestão do PBF, uma vez que é o financiador principal, o responsável pela articulação federativa e pelo desenho normativo do programa. Entretanto, tais características, por si só, não possibilitam definir essa política como centralizada, tendo em vista que, na implementação e gestão dos programas da saúde e da educação, o governo federal também atua da mesma forma.

O modelo de gestão do PBF, após os cinco anos de existência, indica que a descentralização é um princípio basilar. Desde sua concepção, as medidas empreendidas pelo MDS eram voltadas ao fortalecimento da gestão compartilhada, em especial com os municípios. O programa adotou estrutura de incentivos pautada no apoio financeiro e técnico aos governos subnacionais, nos moldes do que preconizavam os estudos sobre descentralização de políticas sociais. De modo geral, pode-se afirmar que o modelo tem alcançado resultados positivos, principalmente no que tange ao Cadastro Único, às condicionalidades e à gestão de benefícios. Embora, em outros aspectos, como programas complementares, fiscalização e pactuação, ainda careça de profundos ajustes.

$\mathrm{O}$ artigo procurou ainda demonstrar que a implementação e a gestão do PBF vão além da pura descentralização, ao incorporar princípios caros às redes de políticas públicas. O Bolsa Família possui uma configuração de inúmeros atores com diversos interesses, mas um objetivo comum: combater a pobreza no país. Esses atores se articulam de formas distintas, seja intragovernamental, entre entes federados, 
ou com a sociedade civil, criando relações que ultrapassam o pressuposto da simples hierarquia. $\mathrm{O}$ modelo do programa exalta a autonomia, ao mesmo tempo em que valoriza a característica de interdependência entre os atores responsáveis pela gestão.

Embora continuem existindo desafios ao programa, tais como a efetiva atuação do controle social e a oferta de programas complementares, a opção pelo fortalecimento de uma ampla gestão compartilhada é uma das principais razões dos resultados positivos que o Bolsa Família vem obtendo desde sua criação.

(Artigo recebido em fevereiro de 2009. Versão final em março de 2009)

\section{Notas}

${ }^{1}$ BrasiL. Ministério do Desenvolvimento Social e Combate à Fome. A Evolução dos Recursos dos Programas de Transferência de Renda. Caderno SUAS, ano 3, nº 3, Brasília: 2008.

${ }^{2}$ Decreto no 5.209 de 17 de setembro de 2004.

${ }^{3}$ Ver Portaria GM/MDS no 666, de 28 de dezembro de 2005, que disciplina a integração do Programa Bolsa Família e do Programa de Erradicação do Trabalho Infantil.

${ }^{4}$ Instrução Normativa Senarc n⿳ำ 01, de 20 de maio de 2005.

${ }^{5}$ Palavra ainda não traduzida para a língua portuguesa, remete-nos ao princípio de que indivíduos e organizações são responsáveis pelos seus atos e devem explicações sobre os mesmos.

\section{Referências bibliográficas}

Abrucio, F. L. . Para além da descentralização: os desafios da coordenação federativa no Brasil. In: Fleury, Sonia (Org.). Democracia, Descentralização e Desenvolvimento: Brasil e Espanha. 1 ed. Rio de Janeiro: FGV Editora, 2006, p.77-125.

ACIR, Advisory Commission on Intergovernmental relations. The condition of contemporary federalism: conflicting theories and collapsing constraints. Washington: 1981.

Affonso, Rui e Silva, Pedro (Org.). Descentralização e políticas sociais. São Paulo: Fundap, 1996.

Almeida, M. H. T. . Federalismo e Políticas Sociais. In: Affonso, Rui de Britto Álvares; Silva, Pedro de Barros. (Org.). Descentralização e Políticas Sociais. São Paulo: Fundap, 1996, v., p. 13-40.

junho de 2005.

. Recentralização a Federação? Revista de Sociologia Política. no 24, p. 29-40,

Arretche, Marta e Rodriguez, Vicente (Org.). Descentralização das políticas sociais no Brasil. São Paulo: Fundap/Fapesp, 1999.

Arretche, Marta. Estado federativo e politicas sociais: determinantes da descentralização. São Paulo: Fapesp, 2000. 
. Federalismo e Políticas Sociais no Brasil: problemas de coordenação e autonomia. São Paulo em Perspectiva, 18(2), p.17-26, 2004.

Bonafont, Laura C. Redes de Políticas Públicas. Madrid: Centro de Investigaciones Sociológicas, 2004.

Börzel, Tanja. Organizing Babylon: on the different conceptions of policy networks. Public Administration, Vol.76, summer 1998, p. 253-273.

Brasil. Ministério do Desenvolvimento Social e Combate à Fome. A Evolução dos Recursos dos Programas de Transferência de Renda. Caderno SUAS, ano 3, no 3, Brasília: 2008.

Cohn, Amélia e Fonseca, Ana. O Bolsa Família e a questão social. Revista Teoria e Debate, nº 57, março/abril de 2004.

FLeury, Sonia. Democracia, Descentralização e Desenvolvimento: Brasil \& Espanha. Rio de Janeiro: Editora FGV, 2006.

Fleury, Sonia e Ouverney, Assis Mafort. Gestão de Redes - A estratégia de regionalização da política de saúde. Rio de Janeiro: Editora FGV, 2007.

Mesquita, Camile Sahb. Contradições do processo de implementação de políticas públicas: uma análise do Programa Bolsa Família 2003 - 2006. Revista do Serviço Público. Brasília 57 (4), p. 465-487 Out/Dez 2006.

SENARC. Instrução Normativa Senarc no 01, de 20 de maio de 2005.

SouZA, Celina. Federalismo, desenho constitucional e instituições federativas no Brasil pós-1988. Revista de Sociologia e Política. Curitiba, v. 24, no 24, p. 105-122, 2005.

World Bank. 2002. Decentralization: What, Why and Where. Disponível em: http:// www1.worldbank.org/publicsector/decentralization/what.htm. Acesso em: 20 de junho de 2008. 


\section{Resumo - Resumen - Abstract}

\section{Programa Bolsa Família: descentralização, centralização ou gestão em redes? Pedro Luiz Cavalcante}

O artigo analisa o processo de implementação e o modelo de gestão do Programa Bolsa Família $(\mathrm{PBF})$, no cerne do debate da centralização-descentralização. A hipótese do estudo é que o PBF não apenas caminhou para o fortalecimento da descentralização, superando alguns desafios da consolidação do "pacto federativo", como também construiu uma configuração mais complexa, próxima à gestão em redes. Para tanto, é apresentada uma discussão teórica acerca do federalismo, da descentralização das políticas sociais e do conceito de redes de políticas públicas. Em seguida, são discernidos os princípios que fundamentaram a concepção do programa, bem como as principais estratégias de implementação. Como conclusão, argumenta-se que, apesar de ainda persistirem desafios à gestão compartilhada, a implementação do PBF se pautou não apenas no princípio da descentralização, como também na transparência, controle e participação popular

Palavras-chave: implementação de políticas públicas, relações federativas, descentralização de programas sociais, redes de políticas públicas.

\section{Programa "Bolsa Família": ¿descentralización, centralización o gestión en redes? Pedro Luiz Cavalcante}

El artículo analiza el proceso de implementación y el modelo de gestión del "Programa Bolsa Familia" (PBF) en el meollo del debate sobre centralización-descentralización. La hipótesis del estudio es que el PBF no sólo siguió hacia el fortalecimiento de la descentralización, superando algunos retos de la consolidación del "pacto federativo", sino también contruyó uma forma más compleja, más cercana a la gestión en redes. Por eso, se presenta una discusión sobre el federalismo, la descentralización de las políticas sociales y el concepto de redes de políticas públicas. Luego, los principios que fundamentaron la concepción del programa son discernidos, además de las principales estrategias de implementación. Para concluir, se argumenta que, pese a que todavía siguen existiendo retos a la gestión compartida, la implementación del $\mathrm{PBF}$ se ha regulado no sólo por el principio de la descentralización, sino también por el de la transparencia, control y participación popular.

Palabras clave: implementación de políticas públicas, relaciones federativas, descentralización de programas sociales, redes de políticas públicas.

\section{“Bolsa Família” Program: decentralization, centralization or network management? Pedro Luiz Cavalcante}

This article analyses the Bolsa Familia's policymaking process and its management framework in the extent of the debate related to centralization and decentralization. The hypothesis of the study is that this social program has focused not only on strengthening the decentralization, surpassing some challenges for the consolidation of the "federative pact", but has also built a complex framework, in close proximity to the network management. In order to do so, the article presents a theoretical discussion about federalism, decentralization of social policies, and a concise concept of policy network. Moreover, the values of the program formulation and the main implementation strategies are described. Therefore, it is argued that, despite the remaining of the shared management challenges, the PBF implementation has been based on decentralization as well as on transparency, social control and participation.

Keywords: policy making, federative relationships, decentralization of social programs, policy network. 


\section{Pedro Luiz Cavalcante}

Doutorando em Ciência Política pela Universidade de Brasília (UnB); mestre em Ciência Política pela UnB; especialista em Administração Pública pela EBAPE/FGV. É membro da carreira de Especialista em Políticas Públicas e Gestão Governamental (EPPGG) e atualmente é coordenador de Estudos Técnicos no Ministério do Desenvolvimento Social e Combate à Fome (SPOA/MDS).

Contato: pedrocavalcante@hotmail.com 